\title{
Hispanic Patient Perspectives of the Physician's Role in Obesity Management
}

\author{
Colton Ragsdale ${ }^{\mathrm{a}}$, Justin Wright ${ }^{\mathrm{b}}$, Gurjeet Shokar ${ }^{\mathrm{b}}$, Rebekah Salaiz ${ }^{\mathrm{b}}$, \\ Navkiran K. Shokar ${ }^{\mathrm{c}, \mathrm{d}}$
}

\begin{abstract}
Background: Little is known concerning Hispanic patients' perceptions about the role of the physician in obesity management. This study seeks to describe the perspectives of Hispanic patients toward weight loss, and what they believe their doctor's role should be in the management of obesity.
\end{abstract}

Methods: A cross-sectional study utilizing semi-structured interviews was conducted in a university-based family medicine clinic. Open-ended questions explored beliefs about the relationship between weight and health, previous weight loss experience, perceptions about the role of the physician in weight loss, past experiences with their physician, and preferences for how a physician could help facilitate weight loss. The free recall listing technique was used to elicit responses. Common themes were identified by a group coding process.

Results: Patients were open to discussion from physicians concerning weight loss but many had not been approached. They wanted assistance from their doctors in the form of dietician referrals, specific weight loss goals, and encouragement. Patients' knowledge about the implications of excess weight on health was lacking.

Conclusion: Hispanic patients want more help and advice from their doctors. General knowledge of the health implications of obesity was lacking, indicating a need for more health education by the healthcare team.

Keywords: Obesity; Hispanic; Perspectives; Management; Physician

Manuscript accepted for publication December 16, 2016

${ }^{\text {aDepartment }}$ of Pediatrics, Greenville Hospital System, University of South Carolina, 701 Grove Road, Greenville, SC 29601, USA

${ }^{b}$ Department of Family and Community Medicine, Texas Tech University Health Sciences Center, El Paso, Paul L Foster School of Medicine, 9849 Kenworthy St. El Paso, TX 79924, USA

'Department of Family and Community Medicine \& Biomedical Sciences, Texas Tech University Health Sciences Center, El Paso, Paul L Foster School of Medicine, 9849 Kenworthy St. El Paso, TX 79924, USA

${ }^{\mathrm{d}}$ Corresponding Author: Navkiran K. Shokar, Department of Family and Community Medicine \& Biomedical Sciences, Texas Tech University Health Sciences Center, El Paso, Paul L Foster School of Medicine, 9849 Kenworthy St. El Paso, TX 79924, USA. Email: Navkiran.shokar@ttuhsc.edu

doi: https://doi.org/10.14740/jocmr2868w

\section{Introduction}

There is a pressing need for obesity interventions to address the growing prevalence of excess weight in the USA, especially among Hispanics, one of the fastest growing racial/ ethnic groups in America [1]. Obesity is a common condition with associated risks of morbidity and mortality. According to data from the Texas Department of State Health, $68.3 \%$ of the Hispanic population in the El Paso region had a body mass index (BMI) of 25 or greater and $33.5 \%$ had a BMI of greater than 30 . These numbers are greater than both the 2010 national (64.3\% and 28.9\%, respectively) and Texas averages (66.6\% and $31.8 \%$, respectively) [2]. Effective physician-centered obesity interventions could provide the solution to our nation's obesity epidemic and improve people's overall health [3]. Physician centered counseling and intervention is associated with improved diet, physical activity, readiness for lifestyle change, and short-term weight loss [4]. Studies have shown that even modest reductions in body weight of $5-10 \%$, as opposed to achieving ideal weight, are associated with clinically significant improvements in health risk factors [5, 6].

While we know that obesity interventions can bring about positive results, many studies have shown physicians often do not provide adequate counsel to obese patients about their weight $[7,8]$. Previous attempts to understand why weight loss interventions are lacking have identified barriers reported by physicians such as lack of time for counseling, lack of resources for referral, limited training and competence, concerns about reimbursement, and beliefs about futility of treatment [7]. Nguyen et al's study revealed that less educated, obese Spanish speaking patients without comorbid conditions were less likely to receive weight loss advice. This could indicate other possible barriers of language and time that physicians might face when working with Hispanics [8]. While these studies provide some insight into physician perceptions about weight loss counseling, they offer little information about what weight management advice patients actually want or need from their physicians.

To date, only a few studies have explored how patients in general perceive physician attempts at obesity intervention [911]. Potter et al found that patients believed that primary care physicians could help them lose weight and wanted more help than they were getting. Yet this study focused on the general population as a whole and only included Hispanics that could read English [9]. Brown et al's study found that some patients 
were reluctant to seek medical help due to their own personal sense of responsibility with their weight [10]. This study however was conducted in the UK and did not include any minority groups. Ward et al focused on obese African Americans' views on obesity intervention. The results of their study highlighted the need for physicians to be culturally aware of potentially offensive techniques and terminology used to counsel African Americans about obesity [11].

Only recently have studies emerged gathering information on what Hispanics think and believe when it comes to obesity management. They have shown that Hispanic immigrants expressed desire for weight loss programs that incorporate traditional foods, support cultural traditions, and include a family focus [12-14]. Common barriers to making long-term dietary changes were the social and family pressures to eat like others and partake in food-centered celebrations [13]. Many of the studies also found a significant lack of information and a great deal of misinformation regarding nutrition and health among Hispanics [12-16]. These studies however did not focus on the health care system and how physicians could educate and facilitate weight loss.

To our knowledge, no study has focused specifically on obese Hispanic patients perceptions regarding physician-guided obesity management. Whether physician-guided weight management treatments are effective and accepted by Hispanic patients will depend on whether physicians are culturally compatible with patient needs and preferences [17]. This has been demonstrated in the past few years by studies implementing culturally appropriate lifestyle interventions among Hispanics $[13,18]$. The purpose of this study was to describe attitudes of Hispanic patients towards weight loss, understand their prior experiences with their doctors, what they believe their doctor's role should be and exactly how they believe their doctor should help them to lose weight. The assessment will be made through brief semi-structured interviews conducted in various health clinics throughout El Paso. Once gathered, the information could prove invaluable to primary physicians as they work to effectively address the issue of obesity among their Hispanic patients.

\section{Materials and Methods}

A cross-sectional study combining qualitative and quantitative methods was conducted to describe Hispanic patients' attitudes and beliefs about obesity and the role of their physician.

\section{Ethics consent and approval}

Ethical approval for the study was obtained from the Institutional Review Board (E13030).

\section{Inclusion criteria}

Participants were Hispanic men and women, 18 - 75 years of age, overweight or obese (BMI greater than 25.0 based on self- reported height and weight), who presented for a primary care visit for any reason.

The study was conducted at a university-based family medicine clinic.

\section{Materials}

A semi-structured interview guide was used to conduct an interview with each participant. This interview guide was based on questions used in prior studies that have been used to identify thoughts, beliefs, and attitudes of patients regarding weight loss [9-11, 19-21]. Four questions covered attitudes about weight loss $[19,21]$, six questions covered the role of physicians in weight loss $[11,20,21]$, three questions covered patients' past experiences with a physician $[10,19,21]$ and two questions elicited what patients wanted regarding weight loss counseling $[10,11]$. Two de novo questions regarding knowledge of and awareness of BMI were developed and included. Patients' medical history, health status and demographic information were also collected by self-report.

\section{Procedure}

Participants were recruited by personal invitation from a trained bilingual research assistant during regularly scheduled clinic visits. Participants were approached in the waiting area of the clinic and asked if they were interested in participating, eligibility was then determined and if eligible they were taken to a private room where informed consent was obtained and the interview was conducted. The interviewer took contemporaneous short notes and all interviews were recorded, transcribed and then translated into English by two separate translators and cross-checked for accuracy.

\section{Analysis}

The free recall listing technique determines participants' understanding of the definition and boundaries of a topic or domain of interest. It is an open-ended interviewing technique in which participants, as a group, generate a list of responses in their own words. Free-recall lists have some important cognitive properties. In particular, items that are most salient to participants are mentioned at the beginning of individual lists and also occur more often across interviews. Items that are not mentioned on the lists are not as salient as items that appear on the lists. Interviewing more participants may increase the number of items, but the list itself becomes stable, and the order of items does not change as new items are added by each new person. The interviews generate many items per participant, maximizing the amount of information collected per individual and allowing for a smaller sample size. The interviewer and the observer recorded comments and phrases contemporaneously, in written format using the participant's own words. The free-recall listing technique lends itself particularly well to transcribing verbatim because the responses 
Table 1. Participant Characteristics

\begin{tabular}{|c|c|c|c|}
\hline Variable & Mean & SD & Range \\
\hline Age (mean) & 56 & 14.76 & $22-75$ \\
\hline \multirow[t]{2}{*}{ BMI (mean) } & 34.58 & 5.88 & $26.37-49.11$ \\
\hline & $\mathrm{n}$ & $\%$ & \\
\hline \multicolumn{4}{|l|}{ Language } \\
\hline English & 10 & 50.0 & \\
\hline Spanish & 10 & 50.0 & \\
\hline \multicolumn{4}{|l|}{ Race/ethnicity } \\
\hline Hispanic & 17 & 85.0 & \\
\hline Non-Hispanic White & 2 & 10.0 & \\
\hline Other & 1 & 5.0 & \\
\hline \multicolumn{4}{|l|}{ Marital status } \\
\hline Married or living with a partner & 11 & 55.0 & \\
\hline \multicolumn{4}{|l|}{ Country of birth } \\
\hline USA & 8 & 40.0 & \\
\hline Mexico & 11 & 55.0 & \\
\hline Other & 1 & 5.0 & \\
\hline \multicolumn{4}{|l|}{ Currently working } \\
\hline No & 17 & 85.0 & \\
\hline Full time & 3 & 15.0 & \\
\hline \multicolumn{4}{|l|}{ Education } \\
\hline USA (mean years) & 13.09 & 1.57 & \\
\hline Mexico (mean years) & 4.78 & 3.27 & \\
\hline \multicolumn{4}{|l|}{ Health status } \\
\hline Poor & 7 & 35.0 & \\
\hline Fair & 5 & 25.0 & \\
\hline Good & 6 & 30.0 & \\
\hline Very Good & 1 & 5.0 & \\
\hline Excellent & 1 & 5.0 & \\
\hline
\end{tabular}

Five most common past medical conditions

\begin{tabular}{|c|c|c|}
\hline Hypertension & \multicolumn{2}{|l|}{12} \\
\hline Diabetes mellitus & \multicolumn{2}{|l|}{11} \\
\hline Arthritis & \multicolumn{2}{|l|}{11} \\
\hline Dyslipidemia & \multicolumn{2}{|l|}{9} \\
\hline Thyroid disease & \multicolumn{2}{|l|}{4} \\
\hline \multicolumn{3}{|l|}{ come } \\
\hline Less than $\$ 10,000$ per year & 12 & 60.0 \\
\hline$\$ 10,000$ to less than $\$ 15,000$ & 4 & 20.0 \\
\hline$\$ 15,000$ to less than $\$ 20,000$ & 1 & 5.0 \\
\hline$\$ 20,000$ to less than $\$ 25,000$ & 1 & 5.0 \\
\hline$\$ 25,000$ to less than $\$ 35,000$ & 1 & 5.0 \\
\hline
\end{tabular}


are in list format and consist of short phrases or brief sentences. We conducted a semantic thematic analysis [22] using a theoretical framework that was informed by prior work in this area [9-11, 19-21]. The coding and data analysis was done by the team on an ongoing basis throughout. Emerging themes were identified by separately reviewing responses to each question and listing unique themes mentioned by the participant. This procedure allowed us to check for inter-rater reliability. Points of disagreement were discussed until a consensual coding was reached. Data collection was continued until saturation in themes was reached. Data were summarized by tabulating the frequency with which themes were mentioned; this is a method of presenting data obtained from the freerecall listing technique.

\section{Results}

\section{Patient characteristics}

A total of 20 interviews were conducted. Thirty percent of participants were overweight and 55\% had a BMI greater than 35 . The average age was 56 . The income level was primarily under $\$ 10,000$ a year, with $65 \%$ of the group meeting this category (Table 1). The majority of participants had hypertension, diabetes or arthritis.

\section{Attitudes and knowledge of weight loss}

The patients' most common response was that extra weight affected their mobility and energy. Very few mentioned that it affected medical conditions such as diabetes, hypertension, or cholesterol. All patients involved in the interviews agreed that they needed to lose weight. Thirty percent knew what a BMI was and $95 \%$ reported that had never been told their BMI by their doctor.

\section{Role of physician}

Most patients agreed that they thought their doctor should be involved weight loss but with varied roles. Some were not sure how the doctor could help since they themselves already knew what they needed to do or thought they knew what their doctor would say or do. Most agreed that their doctors did have the necessary knowledge and if they did not, they should. About half of the patients replied that their doctors did not prioritize weight loss or were unsure of the priority because their doctor had never discussed weight loss with them.

\section{Past experience with physician and weight loss}

Nearly all patients said they had attempted to lose weight with either diet and/or exercise, and a few had undergone gastric bypass operations. Prominent obstacles to losing weight were identified as perceived high costs of a healthy diet, eating a bad diet, using food to cope with emotion or life changes, a lack of mobility, low energy and poor weight loss knowledge. All of the patients were comfortable discussing their weight loss with their doctor and the healthcare team but had never broached the subject with their doctor. A few mentioned that they only wanted their weight addressed if they were asked permission. Sixty percent of the patients remarked that their doctor had never discussed their weight with them. Participants reported that if their physician did mention weight loss, they gave very general tips such as eating less and being more active.

\section{What patients desire from their doctor}

The most common preferences for physician assistance were specific information such as nutritional advice and specific weight loss goals, encouragement to continue progress, and referrals to nutritionists and weight loss experts. Common weight loss motivators and facilitators identified were encouragement from the healthcare team as well as having a support group or partners to join them in weight loss.

\section{Discussion}

Our data show that Hispanic patients in this study want to lose weight and have tried in the past but have been unsuccessful due to a variety of barriers. These findings are similar to those identified in past studies in other groups [9, 12, 14, 23]. While most Hispanics in our group realized that excess weight played a role in decreased mobility and energy, not many were aware of the implications of excess weight on their current medical problems or overall health. Only a few patients realized that their excess weight had a direct impact on their medical issues. Whether this knowledge came from past physician/patient education remains unknown. Regardless, it is worrisome that the majority of participants did not know the implications of weight on their direct health. Our findings are consistent with other studies in the overall lack of awareness of the health consequences of obesity in the Hispanic population $[15,16$, 23]. This observation is important, since diabetes, hypertension, and coronary heart disease are highly prevalent among the Hispanic population $[1,24]$. So it is especially important for the physician and healthcare team to discuss weight management with patients with these conditions.

Many of the patients interviewed had little understanding of what their ideal or healthy weight should be. When asked to define BMI, only a third knew what it was while almost none had been notified about it by their doctor. Using BMI as a teaching tool could demonstrate clearly to patients how much excess weight they have. Interestingly, throughout our interviews many patients admitted they were "heavy" or "overweight" when in fact the majority fit the BMI criteria for being obese. Similar findings from another study showed that USborn obese Hispanics were more likely to perceive themselves as overweight and desire to weigh less than their foreign-born counterparts [16]. Using BMI could provide patients a clear view of where they currently are in their weight status while 
also providing goal oriented steps to gain a healthy weight.

Overall, participants felt comfortable talking about their weight with their doctors or any member of the healthcare team. We found that Hispanic patients trust their doctors and believed they had the knowledge necessary for the health problems they faced. They believed that if weight did affect health, a doctor has a responsibility to bring it up. However, for $60 \%$ of our interviewees, the topic of weight loss had never been discussed by their physicians. This lack of weight loss discussion made about $50 \%$ of our interviewees believe that their doctors did not put weight loss as a priority in their health. Some studies have shown that when physician interventions are done, they focus only on those morbidly obese or those with comorbidities $[8,9]$. From our results, we believe that if doctors made weight loss intervention a priority in their exam regardless of the lack of comorbidities, patients would understand the importance of maintaining a healthy weight allowing prevention of further weight gain.

In our study, we found that similar to patients from other races/ethnicities, Hispanic patients want detailed information such as specific nutritional advice and need specific goals to help them achieve their proper weight [9]. Patients want constant encouragement from their healthcare team to help them continue their progress. When physicians do not have the time or the knowledge to discuss weight loss intervention, patients want referrals to nutritionists and weight loss experts.

We were able to obtain a fair amount of responses to our open-ended surveys to the point that responses became saturated with similar themes. While we are aware that such a small sample size could not possibly represent the variety of views found in the Hispanic population, it does provide a good basis for future study. It is possible that the results obtained could very well be one-sided as they represent a specific demographic that frequents the local health clinic. Looking forward we will need to administer the next phase of our study to a much larger sample size to adequately asses the attitudes, experiences, and desires of the Hispanic population concerning weight loss.

\section{Conclusion}

The results of our study demonstrate that the attitudes, experiences, and desires of the Hispanic population concerning weight loss intervention with physicians, resemble those observed among other groups. Our findings highlight the need for physicians to specifically educate and provide resources to their patients not only concerning the effects of excess weight on health but also where their patients currently stand in their BMI. Such education could provide renewed motivation and concrete goals for weight loss. The Hispanic patients in our study wanted more help and advice from their doctors in the form of dietician referrals, specific weight loss goals, and encouragement throughout the process. Appropriate changes should be made in the physician's practice to address these needs. We strongly believe that continued research into understanding how Hispanic patients can be helped by their physicians will lead to improved weight loss management and overall healthcare of the Hispanic community.

\section{Conflicts of Interest}

None.

\section{References}

1. Flegal KM, Carroll MD, Ogden CL, Curtin LR. Prevalence and trends in obesity among US adults, 1999-2008. JAMA. 2010;303(3):235-241.

2. (CHS) CfHS. Texas Behavioral Risk Factor Surveillance System Survey Data. 2010. https:/www.dshs.state.tx.us/ Layouts/ContentPage.aspx? pageid $=35474 \&$ year $=10 \&$ ris $\mathrm{k}=170$ \&area $=$ EIPaso, 2010.

3. Tsai AG, Wadden TA, Rogers MA, Day SC, Moore RH, Islam BJ. A primary care intervention for weight loss: results of a randomized controlled pilot study. Obesity (Silver Spring). 2010;18(8):1614-1618.

4. Jay M, Schlair S, Caldwell R, Kalet A, Sherman S, Gillespie C. From the patient's perspective: the impact of training on resident physician's obesity counseling. J Gen Intern Med. 2010;25(5):415-422.

5. Drieling RL, Ma J, Stafford RS. Evaluating clinic and community-based lifestyle interventions for obesity reduction in a low-income Latino neighborhood: Vivamos Activos Fair Oaks Program. BMC Public Health. 2011;11:98.

6. Wadden TA, Volger S, Sarwer DB, Vetter ML, Tsai AG, Berkowitz RI, Kumanyika S, et al. A two-year randomized trial of obesity treatment in primary care practice. N Engl J Med. 2011;365(21):1969-1979.

7. Ferrante JM, Piasecki AK, Ohman-Strickland PA, Crabtree BF. Family physicians' practices and attitudes regarding care of extremely obese patients. Obesity (Silver Spring). 2009;17(9):1710-1716.

8. Nguyen HT, Markides KS, Winkleby MA. Physician advice on exercise and diet in a U.S. sample of obese Mexican-American adults. Am J Health Promot. 2011;25(6):402-409.

9. Potter MB, Vu JD, Croughan-Minihane M. Weight management: what patients want from their primary care physicians. J Fam Pract. 2001;50(6):513-518.

10. Brown I, Thompson J, Tod A, Jones G. Primary care support for tackling obesity: a qualitative study of the perceptions of obese patients. Br J Gen Pract. 2006;56(530):666672.

11. Ward SH, Gray AM, Paranjape A. African Americans' perceptions of physician attempts to address obesity in the primary care setting. J Gen Intern Med. 2009;24(5):579584.

12. Agne AA, Daubert R, Munoz ML, Scarinci I, Cherrington AL. The cultural context of obesity: exploring perceptions of obesity and weight loss among Latina immigrants. J Immigr Minor Health. 2012;14(6):1063-1070.

13. Lindberg NM, Stevens VJ, Vega-Lopez S, Kauffman TL, Calderon MR, Cervantes MA. A weight-loss intervention program designed for Mexican-American women: cultural adaptations and results. J Immigr Minor Health. 
2012;14(6):1030-1039.

14. Martinez J, Powell J, Agne A, Scarinci I, Cherrington A. A focus group study of Mexican immigrant men's perceptions of weight and lifestyle. Public Health Nurs. 2012;29(6):490-498.

15. Mama SK, Soltero EG, Ledoux TA, Gallagher MR, Lee RE. Solving the obesity epidemic: voices from the community. Nurs Inq. 2014;21(3):192-201.

16. New C, Xiao L, Ma J. Acculturation and overweightrelated attitudes and behavior among obese Hispanic adults in the United States. Obesity (Silver Spring). 2013;21(11):2396-2404.

17. James KS, Connelly CD, Rutkowski E, McPherson D, Gracia L, Mareno N, Zirkle D. Family-based weight management with Latino mothers and children. J Spec Pediatr Nurs. 2008;13(4):249-262.

18. Corsino L, Rocha-Goldberg MP, Batch BC, Ortiz-Melo DI, Bosworth HB, Svetkey LP. The Latino Health Project: pilot testing a culturally adapted behavioral weight loss intervention in obese and overweight Latino adults. Ethn Dis. 2012;22(1):51-57.

19. Huang J, Yu H, Marin E, Brock S, Carden D, Davis T. Physicians' weight loss counseling in two public hospital primary care clinics. Acad Med. 2004;79(2):156-161.

20. Tan D, Zwar NA, Dennis SM, Vagholkar S. Weight management in general practice: what do patients want? Med J Aust. 2006;185(2):73-75.

21. Thomas AM, Moseley G, Stallings R, Nichols-English G, Wagner PJ. Perceptions of obesity: Black and White differences. J Cult Divers. 2008;15(4):174-180.

22. Braun V, Clarke V. Using thematic analysis in psychology. Qualitative Research in Psychology. 2006;3(2):77101.

23. Lindberg NM, Stevens VJ. Immigration and weight gain: Mexican-American women's perspectives. J Immigr Minor Health. 2011;13(1):155-160.

24. Malnick SD, Knobler $H$. The medical complications of obesity. QJM. 2006;99(9):565-579. 